\title{
Estimating Acacia mangium Plantation's Standing Timber Volume Using an Airborne Hyperspectral Imaging System
}

\author{
Hj. Kamaruzaman Jusoff*
}

Yale University, School of Forestry and Environmental Studies, 205 Prospect St, New Haven, CT 06511, USA

\begin{abstract}
Individual tree mapping in the forest is usually done by several techniques such as the sequential target and point origin mapping. Generally, the estimation of standing timber volume operation is considered a difficult task as ground survey is expensive. Most of this task is being done on the ground and takes a lot of time to be accomplished. However, the use of airborne remote sensing such as the UPM-APSB's Airborne Imaging Spectrometers for Applications (AISA) that plays its part in Global Positioning System (GPS) could change the way on how tree mapping and standing timber volume estimation are done. The general objective of this study is to map the individual wild A. mangium trees and estimate their standing timber volume using the airborne hyperspectral imaging technique. The specific objectives were to assess the capability of UPM-APSB's AISA airborne hyperspectral data in mapping A. mangium plantation and estimate its standing timber volume by delineating the individual trees crown areas. The hyperspectral image of A. mangium plantation in Lebuh Silikon, UPM in ENVI (.img) format taken on February 2004 was enhanced using the ENVI software. The age of the $A$. mangium stand was about 30 years old. Results indicated the presence of 29 canopies of $A$. mangium trees over a 0.8 ha plot. A single crown or canopy represented a single tree. A set of simple linear regression model for predicting volume from the crown area was developed using the 29 samples of tree crown. The value for $\mathrm{r}^{2}$ was 0.801 for this fit of the model, which showed $80.1 \%$ erratum data could be evaded. The equation developed in this study was $\mathrm{V}=$ $0.1045+0.0111(\mathrm{CA})$ where it provided a mean for predicting volume from the crown size measurement using the airborne sensor. The total standing timber volume mapped and quantified by the UPM-APSB's for the study site of 0.8 ha $A$. mangium plantation was about $20.73 \mathrm{~m}^{3}$ with a mapping accuracy of $80.45 \%$. In practice, users of airborne hyperspectral data can now predict the timber volume by measuring tree crown size using ENVI software and apply the appropriate equation developed from linear regression as the indirect method of timber volume estimation. Further work in this area is to estimate the above ground biomass, carbon sequestration and biodiversity of planted A. mangium plantations in Malaysia.
\end{abstract}

\section{INTRODUCTION}

Other than the natural forests, Malaysia has also ventured into forest plantation. Forestry Departments were the main agencies involved in developing tree plantations. In 1982, the Forestry Department of Peninsular Malaysia launched the Compensatory Forest Plantation Program by planting fast-growing tropical hardwood species, such as Acacia mangium, Gmelina arborea and Paraserianthes falcataria [1]. In 1996, a total of 0.07 mil. ha of forested area had been converted into plantation forests in Peninsular Malaysia. Forest plantations in the East Malaysian states of Sabah and Sarawak were established since 1973 and 1981, respectively. In Sarawak, the total forest plantation established is about 10,000 ha, which consists of exotic species such as A. mangium, G. arborea, P. falcataria, Swietenia macrophylla (Mahogany), A. cunninghemii, and some indigenous species such as $S$. macrophylla (Engkabang) and Durio zibenthinus (Durian). The Sarawak Forestry Department has a plan to establish 2,000 ha annually in the Permanent Reserve Forests that have been affected by shifting cultivation. In the state of Sabah, a total of 113,811 ha of forest plantations had been established of which 90,026 ha $(79.9 \%)$ is covered by fast

*Address correspondence to this author at the Yale University, School of Forestry and Environmental Studies, 205 Prospect St, New Haven, CT 06511, USA; E-mail: kjusoff@yahoo.com growing species such as A. mangium, Tectona grandis and rattan. In Sabah, nearly 200,000 ha of degraded lands that resulted from shifting cultivation activity were reforested. The task was set up by the Sabah Forestry Development Authority (SAFODA) in 1976. In the 1980s, more commercial forest plantation ventures were established. The first pulp and paper mill was set up in Sipitang by the Sabah Forest Industries (SFI), a State owned company. It has now been privatised. SFI expects to reforest up to 130,000 ha with industrial forest plantations, mainly with A. mangium.

According to information released by the Forest Department, Peninsular Malaysia, forest plantations covered 74,022 ha in 2000 . The data obtained by the survey conducted under this study indicate a slightly higher area of 75,672 ha for 2001. More than 15,000 ha were planted in 1988 and more than 10,000 ha in 1985 , which is 20 and $15 \%$ of the total plantation areas, respectively. Most of the plantations were established during the first phase of the Compensatory Forest Plantation Program between 1982 and 1988. Since 1989, annual planting rates have not exceeded 7,000 ha. In the 1980s large areas have also been devoted to Acacia mangium and other fast growing general utility timber species under the Compensatory Forest Plantation Scheme, funded by the Asian Development Bank. The species preferred by all planters is obviously Acacia mangium. 
Inventory information on stand growth is required for planning timber harvest rotations. Stumpage inventories are the most likely to be used to determine the current value of timber in plantation evaluations. Aerial photographs are commonly used for plantation planning, and are available from land management agencies. Aerial photographs are useful in cases where the plantation area is large or broken up by watercourses or failed plantings. Aerial photographs enable to identify areas within the plantation where no trees are growing, such as roads, clearings, and therefore better estimate the net stocked area. On reasonably flat ground, aerial photos can be used to draw the plantation boundary onto a map of equivalent scale and calculate the area using the dot grid provided [2]. According to [3], a forest inventory for a $60 \mathrm{~km}^{2}$ size eucalyptus plantations in Portugal was carried out based on airborne laser scanner and intensive field work and additional data from the forest management authority. Since eucalyptus tree crowns within planting rows have a small diameter, the individual trees were modeled by only one parameter, the tree height. The verification of the results from the automatic single tree detection showed a correctness of $93 \%$. The calculation of timber volume for several reference stands with a total size of 75 ha yielded to a correctness of again $93 \%$. Meanwhile, in another study by [4], he reported that remote sensing is a cost efficient source of information for large-area forest inventories and satellite image data hve been widely applied in various inventory tasks. Remote sensing and GIS provide for the continuous monitoring of forest developments by detecting changes and for the integration of the results into existing databases. The plantation may have homogenous blocks of different age groups and tree species, which allow identifying the features more easily and prominently than in complexities of natural stand. Forest management requires more information about the extent, composition, density, age variation and trends in the plantation forestry [5]. Light detection and ranging (LiDAR) are relatively new remote sensing tools that have the potential for use in the acquisition of measurement data for inventories of standing timber, biomass, basal area, and tree and stand height estimates. Mounted in aircraft, LiDAR (Light Detection And Ranging) technology uses pulses of light to collect data about the terrain below. LiDAR is capable of locating tree crowns with an accuracy of more than 90 percent for common spacing in pine plantations [6].

Generally, the pre-harvest estimation of standing timber volume is crucial for successful operation especially in the forest but constitute a difficult task as ground survey is expensive. Accurate pre-harvest timber yield or standing timber volume estimates are crucial as they constitute the basis for harvest maps and help balance harvest cost and incomes from wood sales. Ground surveys or manual methods in plantation areas are time consuming and costly. Spatial data mapping of individual tree crown delineation for A. mangium plantation is useful in order to estimate timber yields accurately and help balance harvest cost. Spatially precise estimates could also help in achieving sustainable forest management. Generally, the pre-harvest estimation of standing timber volume is crucial for successful operation especially in the forest but constitute a difficult task as ground survey is expensive. Accurate pre-harvest timber yield or standing timber volume estimates are crucial as they consti- tute the basis for harvest maps and help balance harvest cost and incomes from wood sales.

The overall objective of this study is therefore to map the individual tree and estimate the standing timber volume of a wild A. mangium stand in UPM. The specific objectives are two-folds, namely (i) to assess the capability of UPMAPSB's AISA airborne hyperspectral data in mapping $A$. mangium plantation and estimate its standing timber volume, and (ii) to identify and quantify the individual tree crown areas delineation for A. mangium plantation.

\section{METHODS AND MATERIALS}

\section{Description of Study Area}

The study area selected was a wild unmanaged A. mangium plantation situated in Lebuh Silikon, Universiti Putra Malaysia. The location of the A. mangium plantation is shown in Fig. (1).

\section{Equipments and Instrumentations}

Suunto Clinometer was used to measure the bole height of trees or merchantable height of trees. It had two units of measurements, i.e. in percent and in degree. Meanwhile, a measuring tape was used to measure the distance between trees in the bearing distance mapping method performed on the ground. It was also used to measure the tree crown diameter on the field. It has a maximum length of $30 \mathrm{~m}$. The diameter tape was used to measure the diameter at breast height (DBH) of trees in $\mathrm{cm}$. The Global Positioning System (GPS) was used to determine the position and coordinate (longitude and latitude) of the trees on the field.

\section{Software}

ENVI Version 4.0 is the acronym for Environment for Visualising Image. It was used to process the raw hyperspectral data, including the radiometric correction, band combination, image enhancement and several basic processing systems that are commonly used for data analyzing. ENVI was created by Research Systems Incorporation (RSI), a Kodak Company that is dedicated to improving the imaging technology for remote sensing. It was the state of the art image processing system that is designed to provide the comprehensive analysis of satellite and airborne remote sensing data.

\section{Data Acquisition, Image Processing and Enhancement}

Hyperspectral images from the UPM-APSB's AISA sensor of the A. mangium plantation were used in this study. These images had been captured on $18^{\text {th }}$ February 2004 using UPM-APSB's AISA (Airborne Imaging Spectrometer for Applications). The airborne hyperspectral imaging sensor was placed on an aircraft with a $1 \mathrm{~m}^{2}$ spatial resolution. Reconstruction, restoration and/or correction of radiometry and geometry were undertaken in the process of pre-processing. Three steps were followed in the geometric correction which was undertaken to avoid geometric distortions from a distorted image, and was achieved by establishing the relationship between the image coordinate system and the geographic coordinate system using calibration data of the sensor, measuring data of position and attitude, ground control points, atmospheric condition etc. 


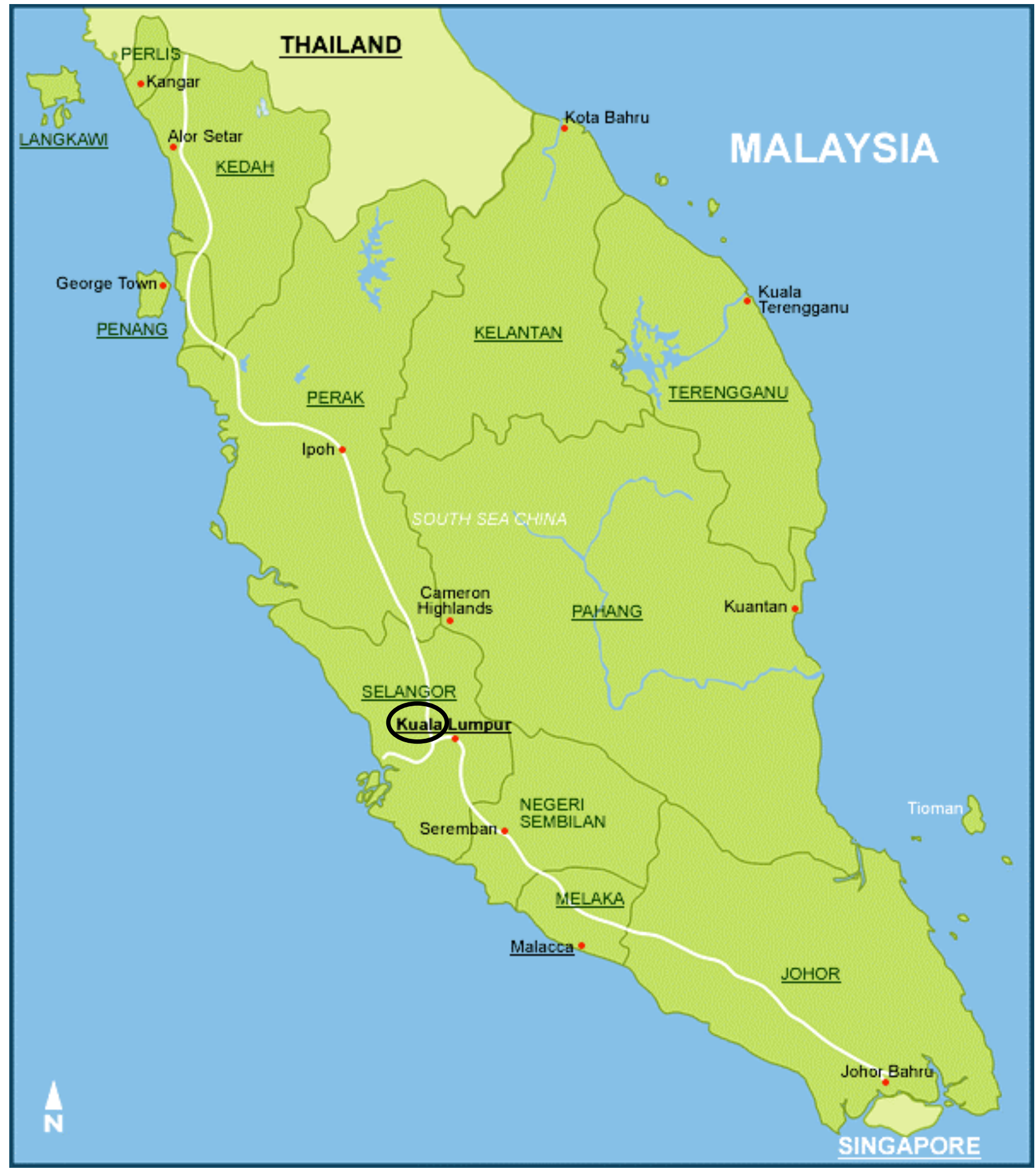

Fig (1). A map of P. Malaysia showing the location of the study site in black circle.

Image enhancement can be defined as conversion of the image quality to a better and more understandable level for feature extraction or image interpretation, while radiometric correction is to reconstruct the physically calibrated value from the observed data. On the other hand, feature extraction can be defined as the operation to quantify the image quality through various parameters or functions, which are applied to the original image. Image enhancement is used to make it easier for visual interpretation and understanding of imagery. There are numerous procedures that can be performed to enhance an image. However, they can be classified into two major categories: point operations and local operations. Point operations change the value of each individual pixel independent of all other pixels, while local operations change the 
value of individual pixels in the context of the values of neighboring pixels. Common enhancements include image reduction, image magnification, transect extraction, contrast adjustments (linear and non-linear), band rationing, spatial filtering, fourier transformations, principle components analysis, and texture transformations [7]. These processes can be considered as conversion of the image data. Image enhancement is applied mainly for image interpretation in the form of an image output, while feature extraction was normally used for automated classification or analysis in a quantitative form. Typical image enhancement techniques include gray scale conversion, histogram conversion, color composition, color conversion between RGB (Red, Green, Blue) and HIS (Hyperspectral Imaging Sensors), etc., which are usually applied to the image output for image interpretation. Image enhancement, spatial and geometric transformation and/or data compression are normally required to generate a thematic map or database.

Hyperspectral remote sensing data, generated by imaging spectrometers, cover the full solar reflected portion of the spectrum with high spectral resolution. They provide rich information on ground cover types and make possible detailed study and monitoring of the Earth. However, data analysis and image classification become difficult due to the high dimensionality resulted by using hundreds of spectral bands. However, with hyperspectral data, the performance of parametric classification technique approach largely relies on two factors. One is that the class data must be approximately unimodal. Secondly, a large enough number of training samples for each class is required in order to obtain reliable statistics estimation. Image features are categorised, which is called labeling in image processing, using those techniques of learning, classification, segmentation and/or matching. There are two general types of classifications: unsupervised and supervised. In both cases, previous knowledge of the imaged scene is highly desirable. Unsupervised classification algorithms compare pixel spectral signatures to the signatures of computer determined clusters and assign each pixel to one of these clusters. Knowledge of the materials contained within the scene is not needed beforehand as the computer assesses the inherent variability and determines cluster identification. Classified distribution maps then require knowledge of the scene area in order to determine what each class (i.e. cluster) may represent in the real world. Conversely, supervised classifications require up-front knowledge of the scene area in order to provide the computer with unique material groups or what are called "training classes". Regions containing a material of interest within a scene are delineated graphically and stored for use in the supervised classification algorithm. The resulting classification maps were checked using ground verification information or ground verification and field validation surveys. In this study, supervised classification was used to delineate the crown areas of individual $A$. mangium.

\section{Ground Verification}

Ground verification is the notion of ground truth being a quick reference to sensor types used to acquire the data to be analyzed. Samplings plots of trees identified from the supervised classification were chosen for examination on the ground. The samples represented by each tree were used for testing the accuracy of the mapping, and to increase the ac- curacy of interpretation. Field sampling was conducted to provide ground verification on UPM-APSB airborne hyperspectral sensing data, and to calibrate and verify the digital signature of the airborne data to enable image analysis.

Sample plot was established as "training sites" to correlate data from field sampling with airborne remote sensing data of the training sites. Trees, which are delineated in the airborne hyperspectral image data, were measured. The position of the individual trees, diameter at breast height (DBH), crown area and height of trees with stem diameter above 25 $\mathrm{cm}$ were enumerated. From the ground verification data, the volume for each sampled trees was estimated using a specific volume timber equation for A. mangium species. Based on [8], the timber volume equation used for this study is as follows:

$\mathrm{V}=0.00006\left(\mathrm{D}^{2} \mathrm{H}\right)^{0.934}$

where;

$$
\begin{aligned}
& \mathrm{V}=\text { volume } \\
& \mathrm{D}=\text { diameter at breast height (DBH) } \\
& \mathrm{H}=\text { the height of tree in meter }
\end{aligned}
$$

The volume equation for Acacia mangium plantation derived by [8] was chosen in this study due to the high $\mathrm{r}^{2}$ value (0.9988). There exists a strong correlation between volume and diameter at breast height (dbh) and the height as measured. Based on the crown areas and volume estimated from the ground verification data, a linear regression model was derived using Excel or SPSS software to obtain the relationship between crown areas and volume of trees.

\section{RESULTS AND DISCUSSION}

\section{Image Enhancement and Band Combination}

The Sobel Filtering with band combination R19G11B2 was used to make the edges clearer and to get a shaper image for further processing. In a simple three-band image (Red, Green, Blue), it is easy to see that there are areas that have similar spectral characteristics. Bright red areas on the image represent high near-infrared reflectance, usually corresponding to healthy vegetation. Fig. (2a) showed the raw image of Acacia mangium plantation in Lebuh Silikon, UPM and its surrounding from UPM-APSB's AISA airborne hyperspectral taken on 18 February 2004 before enhancement. A better image result was obtained after the image enhancement was performed (Fig. 2b).

\section{Spectral Signature Development Profile of $A$. mangium}

Fig. (3) showed the spectral signatures derived from the UPM-APSB's AISA airborne data for some of the Acacia mangium trees available in this study site. It can be clearly seen that $A$. mangium species has it own unique spectral reflectance that made it possible to be differentiated from others. For example, the area of $A$. mangium plantation can be easily distinguished from the other land areas with its green colour reflectance occurring in the middle of the whole image.

\section{Sample Plot Establishment}

One sample plot was established in the middle of the $A$. mangium plantation that covered a big part of the whole 
plantation area. The location of this plot was selected from the airborne hyperspectral image data using ROI that was provided in ENVI software. The size of the sample plot was 0.8 ha with longitude and latitude N2 ${ }^{\circ} 59^{\prime} 55.08^{\prime \prime}$ N2 ${ }^{\circ} 59$ '57.56”, E10143'13.50" - E10143'16.70”.
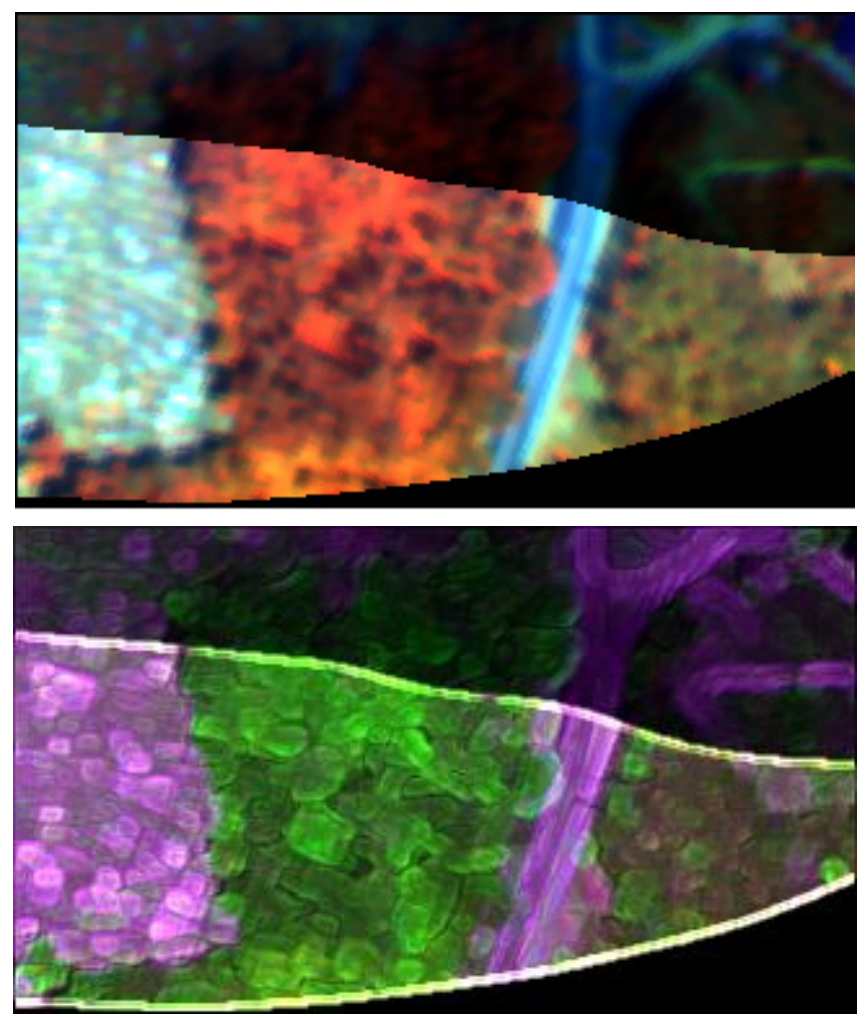

Fig. (2a,b). Raw data (image before enhancement) with a R19G11B2 band combination and after enhancement with a Sobel $75 \%$ R $10 \mathrm{G} 16 \mathrm{~B} 8$ band combination.

\section{Canopy Crown delineation}

The image for the sample plot with band combination R10G16B8 had been enhanced again to make the crown delineation sharper and easier to be delineated using ENVI. This time the band combination had been changed to R12G6B11 and a better image appeared as shown in Fig. (4). The image enhancement is the critical and important part in the advanced image processing because it will influence the results of the study. After the image is successfully enhanced, the canopy delineation process was then carried out using Regions of Interest (ROI) method of image processing with ENVI software. There were 29 canopies of sampled Acacias that had been delineated. From the ROI processing, the areas of individual crown can be measured automatically. There were 29 samples of individual tree crown delineation (Fig. 4) that was produced by overlaying the ROI. Each tree crown sample was marked with a number to ease in the identification and mapping the individual tree crown areas.

\section{Field Sampling}

The GPS details of the ground verification data mapped were recorded and obtained from the field survey. A total of 29 samples of $A$. mangium trees were enumerated with the mean volume per tree is $0.57 \mathrm{~m}^{3} /$ tree.
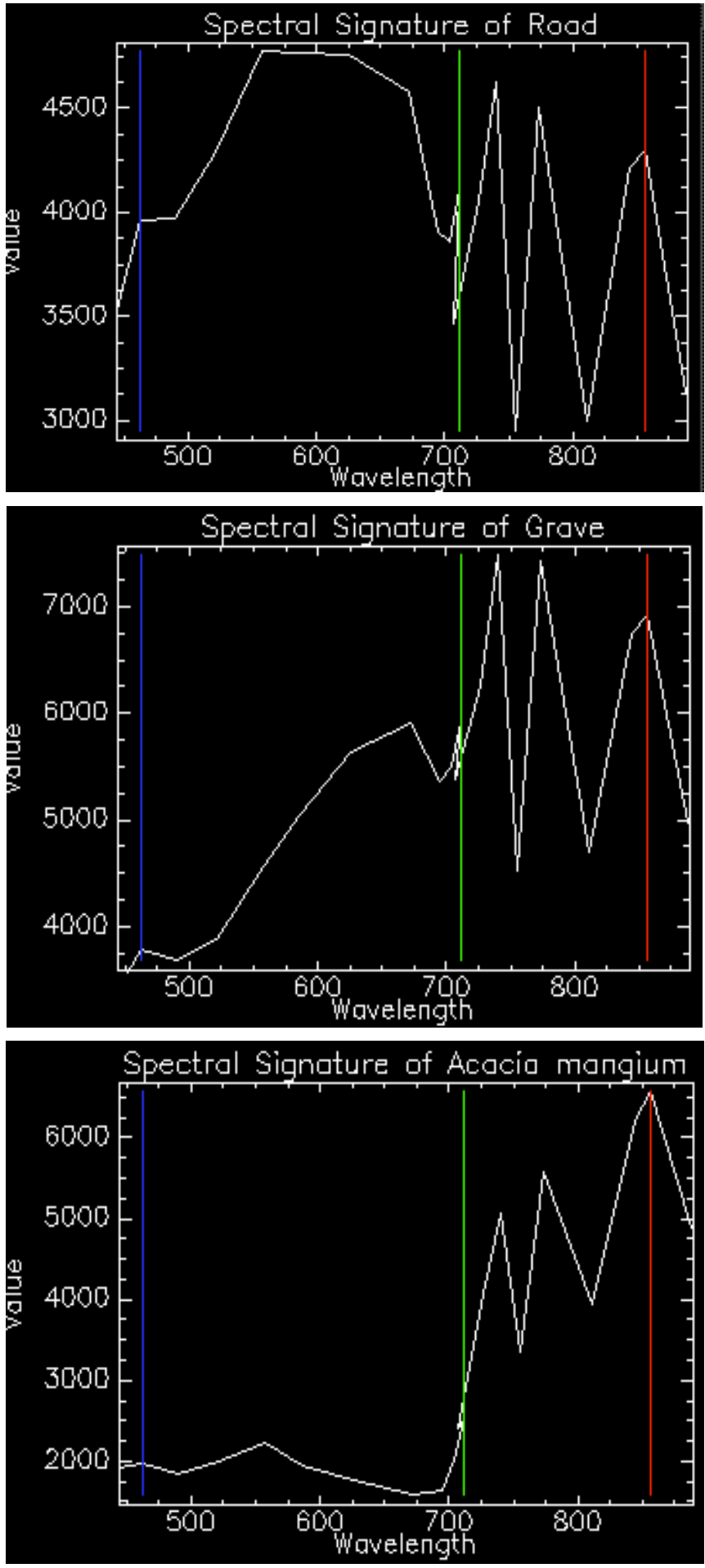

Fig. (3). Spectral signature profile development of individual $A$. mangium trees in relation to the road and graveyards surrounding the wild Acacia plantations.

\section{Regression Model for Volume Estimation}

A set of simple linear regression models for predicting standing timber volume from crown areas was developed for A. mangium plantation as shown in Fig. (5). According to [4], a simple linear model that predicts dbh from crown diameters measured on aerial photos can provide an indirect 


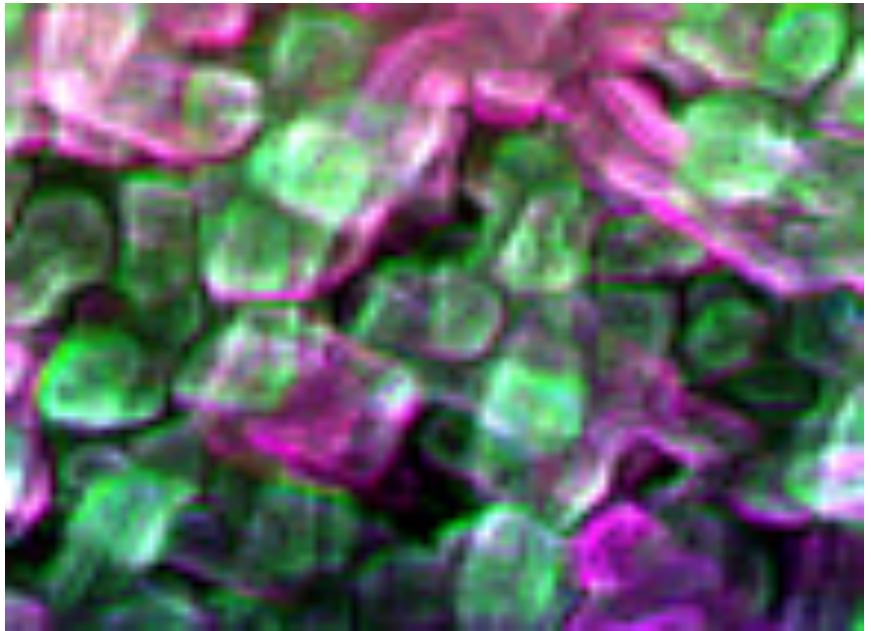

Fig. (4). Sample plots with band combination R12G6B11 and 2x Sobel filter.

method of estimation that can be used to determine values for the basal area and volume of individual trees. Summary statistics of the regression analysis indicate that the models express the relationships reasonably well. To study the relationship between volume and crown area, only 29 trees were used. This calculation was done by referring to a straight line equation as follows in Eqn. 1:

Vol. $=\mathrm{a}+\mathrm{b}(\mathrm{CA}) \ldots \ldots \ldots \ldots \ldots . .$. Eqn. 1

where;

$$
\begin{aligned}
& \text { Vol }=\text { Volume of tree }\left(\mathrm{m}^{3}\right) \\
& \mathrm{CA}=\text { Crown Area }\left(\mathrm{m}^{2}\right)
\end{aligned}
$$

The value for $\mathrm{r}^{2}$ was 0.801 for this fit of the model, which showed $80.1 \%$ erratum data can be evade. The equation for linear regression model in this study is as follows:

Vol. $=0.1045+0.0111(\mathrm{CA}) \ldots .$. Eqn. 2

The equations developed in this study provide a means for predicting volume from crown areas measurement. Scattered plots of the data exhibit a linear relationship within the range of the data. Estimates of individual tree crown areas were obtained from ground measurements. Volume could be estimated by measuring crown areas, converting it to $\mathrm{m}^{3}$ using ENVI software and applying the appropriate equation as Eqn. 2.

\section{Tree Stocking and Timber Volume Estimation}

The total number of individual A. mangium trees mapped from the UPM-APSB's sensor for a 0.8 ha plot size was 29 . With a mean volume per tree of $0.57 \mathrm{~m}^{3}$, the total timber volume for the 0.8 ha plot size was easily estimated as 16.58 $\mathrm{m}^{3}$. This implies that the plantation area had a tree stocking of $20.73 \mathrm{~m}^{3} / \mathrm{ha}$. According to a case study in Malaysia by [9], the mean timber volume for a 15 years old $A$. mangium plantation was $229 \mathrm{~m}^{3} / \mathrm{ha}$. Compared to this value, there was only $10 \%$ of such volume of $A$. mangium plantation in Lebuh Silikon, UPM. This is probably due to the fact that $A$. mangium plantation in UPM is not well managed and the age of the plantation is almost 30 years old. Some of the old $A$. mangium trees in the stand were dead and there was evidence of successions of many pioneer species such as Maca- ranga sp. Some species like Mallotus macrostachyus were also found in the plantation area especially in the open areas.

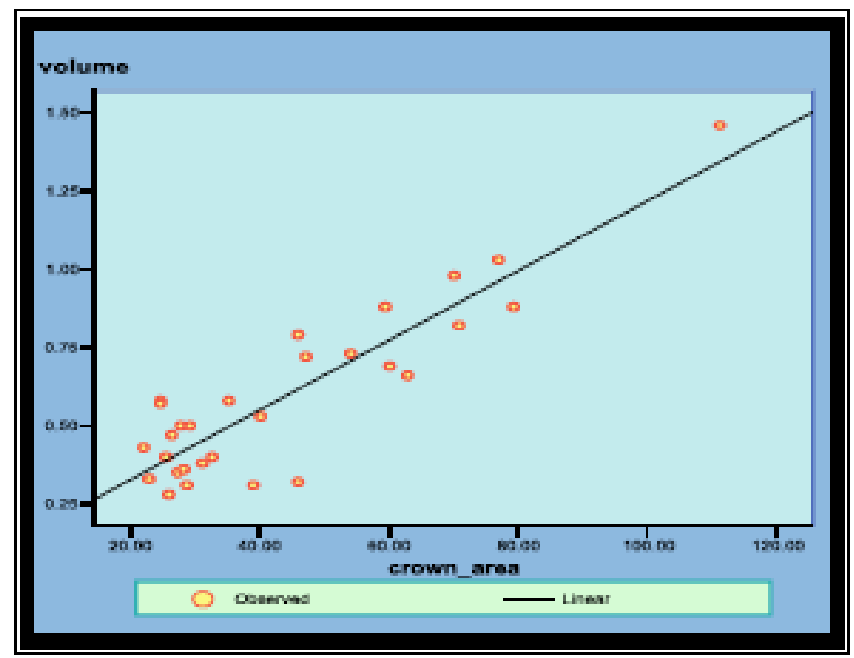

Fig. (5). Regression model for standing Acacia timber volume estimation.

\section{Accuracy Assessment}

Based on total data for 0.8 ha plot, 29 samples were used to calculate the relationship of linear correlation between volume and crown areas as has been shown in Fig. (5) earlier. To obtain the standing timber volume, the mean crown size values from airborne hyperspectral data were put into the equation. The accuracy was tested using an Aggregate Different formula used by [10] as follows:

AGG. Different $=[(\mathrm{MCA}$ from Image

- MCA from GSP)/MCA from GSP] x 100

$$
\begin{aligned}
& =[(44.00-52.6) / 44.00] \times 100 \\
& =-19.55 \%
\end{aligned}
$$

The value - 19.55 shows that about $19.55 \%$ of the 29 sampled data from the ground sampling did not match with the data from the airborne hyperspectral image. This implies that the accuracy of the standing timber volume estimation for the wild $A$. mangium plantation in Lebuh Silikon, UPM using UPM-APSB's AISA airborne hyperspectral data was $80.45 \%$ accurate.

\section{CONCLUSION}

Based on this preliminary analysis and compilation of data from field sampling, a simple linear model that predicts volume from crown areas measured indirectly from airborne hyperspectral data can provide an indirect method of estimation. The UPM-APSB's airborne hyperspectral data is capable of identifying, mapping and estimate the standing timber volume on $A$. mangium plantation in Lebuh Silikon, Universiti Putra Malaysia, Serdang. The total standing Acacia timber volume mapped and quantified by the UPM-APSB's airborne sensor for the study site is about $20.73 \mathrm{~m}^{3}$ per ha with a mapping accuracy of $80.45 \%$.

\section{REFERENCES}

[1] Thai SK, Mahdan B, Ridzuan, S. Planting of Acacia mangium for General 1997. Utility Timber and Reconstituted Wood Products. Paper presented at the Seminar on Commercial Cultivation of Teak, 
Sentang, Acacia and Hevea for Timber. Kuala Lumpur. 9 January 1997.

[2] Abed T, Stephens, N.C. Tree measurement manual for farm foresters. Parsons M, Ed. National Forest Inventory, Bureau of Rural Sciences. $2^{\text {nd }}$ ed, Canberra 2003 p. 78

[3] Wack R, Schardt M, Barrucho L, Lohr U, Oliveira T. Forest Inventory for Eucalyptus Plantations based on Airborne Laserscanner Data. Insitute of Digital Image Processing, Joanneum Research, Austria. 2003.

[4] Tomppo E, Multisource national forest inventory of Finland. In: Proceedings of the Ilvessalo Symposim on National Forest Inventories, 17-21 Aug, 1992, Finland. The Finnish Firest Research Institute, Research Papers, 1993; 444: 52-60.

[5] Hock B, Payn T, Dunningham A. Research on spatial analytical tools for New Zealand plantation forests, Presented at the 10th Colloquium of the Spatial Information Research Centre, New Zealand, 16-19 1998.

[6] Parker RC. Computer automation of a LiDAR double-sample forest inventory. Forest and Wildlife Research Center, Bulletin FO275, Mississippi State University. 2006; 19.
[7] Jensen JR, Jackson, M.W. Introductory Digital Image Processing: The Remote Sensing Process, $3^{\text {rd }}$ ed. Department of Geography University of South Carolina Columbia, South Carolina. 1996.

[8] Chongrak W, Somphat K, Ladawan P, Sakhan T, Monton J. Effect of Thinning on Growth and Yield of Acacia mangiumDipterocarpus alatus Mixed Plantation. Trat Agroforestry Research Station (TAfRS), Kasetsart University Research and Development Institute (KURDI), Chattuchak, Bangkok, Thailand. 2005; 8.

[9] Krishnapillay D.B. Case Study of the Tropical Forest Plantations of Malaysia. Forest Plantations Working Papers (FP/23). Forestry Department, Food and Agriculture Organization of the United Nations. Varmola M, Ed. June 2002, 1998; 48.

[10] Azuan MS. Crown Diameter-Basal Diameter Relationship of NonDipterocarp of Hill Dipterocarp Forest in Pahang. (Bachelor Thesis), Faculty of Forestry, Universiti Putra Malaysia, Serdang, Selangor, Malaysia. 2005.

(C) Hj. Kamaruzaman Jusoff; Licensee Bentham Open.

This is an open access article licensed under the terms of the Creative Commons Attribution Non-Commercial License (http://creativecommons.org/licenses/bync/3.0/) which permits unrestricted, non-commercial use, distribution and reproduction in any medium, provided the work is properly cited. 